greater part of the Midland Counties, and the north of Ireland, temperature was also below the average in December, whilst in the north-west of England and over a great part of the north of Scotland each of the six months was below the average. There was no part of the British Islands, except the Channel Islands, in which the temperature for each week, from the commencement of January until the third week in March, did not fall to the freezing-point or below, whilst in the south-west of England there was not a single exception after the first week in October, and in the east of Scotland, the north-east and north-west of England, the thermometer fell to $32^{\circ}$ or below in each week from the commencement of November. The lowest shade-temperatures observed in the British Islands were: in January, $-2^{\circ}$ at Braemar on the Igth, and $\mathrm{I}^{\circ} \mathrm{I}$ at Alston on the 20 th ; in February, $2^{\circ} .5$ at Braemar and $7^{\circ} .1$ at Alston on the 5 th ; in March, $-2^{\circ}$ at Alston and $1^{\circ} \cdot 2$ at Buxton on the 7 th, and $2^{\circ}$ at Braemar on the I2th. There were extremely few instances of the temperature falling below $5^{\circ}$; but temperatures below $10^{n}$ were observed in January and March over the greater part of Great Britain.

From the commencement of January to the middle of March there was almost continuous frost, and during this period it froze for upwards of 60 nights at many places in the British Islands. At Great Berkhamsted the minimum temperature registered $32^{\circ}$ or below in January 22 days, February 23 days, March I 8 days, making a total of 63 days between January 3 and March 18 ; whilst on the grass it froze for 73 consecutive nights, from January 5 to March 18. At Cheadle in Staffordshire, Churchstoke in Montgomery, Llandovery in Carmarthen, and Great Berkhamsted in Hertfordshire, it froze for 33 consecutive nights, from February 14 to March 18, whilst at very many stations the frost continued 30 days or more. In Great Britain the longest period of frost occurred between the middle of February and the middle of March, but in Ireland it occurred generally in January. At Greenwich it froze on 28 consecutive days from February 19 to March 18; the observations from 1845 do not show another instance of frost continuing for so long a period without interruption. The only instances of 20 or more consecutive days are :-

24 days in 1858 , from February 17 to March 12 . 22 days in 1879 , from November 20 to December II. $2 \mathrm{I}$ days in 1855 , from January 14 to February 3. 21 days in 1878 , from December 6 to December 26 .

For the three months from January to March there are but few years since 1845 that have a period of continuous frost of one-half the length of that in 1886 . The years with fifteen days or more are respectively :-

I 886 (28), I 858 (24), I 855 (21), I 86I (I9), I 88I (I6).

Taking the actual days with frost at Greenwich, irrespective of continuity, there was frost on 53 days in the present year (1886) from January to March. In I 855 the number of frosts in the corresponding period was 58 , but the only other instance of more than 50 days was in 1858 , when the number was 53 .

Probably the most interesting feature in connection with the past winter was the excessively cold weather experienced over the whole country at the commencement of March. The Greenwich observations from I8I4 only show two instances of a similarly low temperature-these were in 1814 and 1845 . The unusual frequency with which snow fell was also a matter of interest, and the heavy drifts occasioned serious blocks on many of the northern railways.

The records of the London Skating Club show that there was skating on the Club water in Regent's Park on 38 days during the winter, and I885-86 was the only winter in which there was skating in each of the four months from December to March since the formation of the Club in 1830 , and the only March records of skating in the 56 years are 16 days in 1886,12 days in 1844,10 days in 1858 , and $\mathrm{I}$ day in $\mathrm{I} 8533^{\circ}$ On a pond at Pinner there was almost continuous skating for 3 months, and and at Rickmansworth for about 70 days, but at both places the ice was most carefully nursed. On January 7 there was safe skating on snow-ice after one night's frost.

The temperature of the water in the Thames at Deptford was, on the mean, slightly in excess of the air. From January 8 to March 20 the entire range was from $40^{\circ}$ to $34^{\circ}$; and from March 1 to 19 the maximum temperature was $36^{\circ} \cdot 5$ and the minimum $35^{\circ}$, showing a total range of $I^{\circ} \cdot 5$.

The recent temperatures observed at several stations over England show that at $\mathrm{I}$ foot below the surface the greatest cold for the winter was reached during the first 17 days of March. The mean was generally about $2^{\circ}$ in excess of the mean air temperature. In January the earth temperature at 1 foot was from $2^{\circ}$ to $3^{\circ}$ below the average over the whole country, whilst in February it was from $4^{\circ} .5$ to $6^{\circ} .5$ below the average ; the first 17 days of March, however, show a much larger defect on the average, the deficiency ranging from 6.3 at Lowestoft to $8^{\mathrm{c}} .5$ at Norwood. The temperature of the soil at 2 feet was generally about $2^{\circ}$ in excess of that at I foot.

The logs of ships traversing the North Atlantic show that the abnormal conditions which prevailed over the British Islands and indeed over nearly the whole of Europe extended also a considerable distance to the westward. They show a decided tendency to a low barometer, during the early months of 1886 , in the locality where a high barometer generally prevails, and to the north of this low barometer strong and persistent easterly winds were experienced. These facts tend to show a general reversal of conditions over the Atlantic which would doubtless be very intimately related to our own exceptional weather.

\section{THE ASTRONOMICAL DAY}

$T H E$ recently published report of the Science and $A r \hat{\imath}$ Department contains some most important information showing what the recent Government action has been in relation to the resolutions passed at the Washington Conference.

The first letter that we need refer to is one from the Astronomer-Royal, in April last year, suggesting that reference should be made to various scientific Societies, in order to obtain an authoritative expression of opinion from the scientific men in this country interested in the question. This was followed by a meeting of the committee appointed to advise the Science and Art Department on the matter. The following resolution was adopted by the committee, which consisted of Prof. Adams, the Astronomer-Royal, General Strachey, Captain Sir Frederick Evans (since deceased), Captain Wharton (the Hydrographer), and Colonel Donnelly :- "The committee recommend that the report of the British Dele. gates to the Washington International Prime Meridian Conference, with the resolutions adopted by that body, be communicated to certain Departments of State, learned Societies, telegraph companies, \&c., and that they be informed that the resolutions appear to be such as commend themselves for adoption; but before informing the American Government to that effect they would be glad to receive their opinions on the subject."

The Science and Art Department then addressed a letter to various public offices, scientific bodies, and telegraph companies. Their replies may be thus con densed.

The Eastern Telegraph Company, and the Eastern Extension, Australian, and China Company, state that they have always adopted the twenty-four-hour system in timing their messages, thus avoiding the necessity of signalling the letters a.m. and p.m. 
The Society of Telegraph-Engineers and Electricians cordially approve of the first six resolutions of the Washington Conference, but they reserve their opinion as to the seventh (the one referring to the application of the decimal system to space and time).

The Royal Astronomical Society forwards the following resolution:-

"The Council of the Royal Astronomical Society desire to express their concurrence in the resolutions of the Washington Conference, and consider it desirable that the reckoning of astronomical time from mean midnight be adopted in the Nautical Almanac for I 890, the earliest practicable date, and that it be thenceforward adopted by astronomers."

The India Office writes that "the Government of India will be perfectly prepared to accept whatever conclusions may be arrived at by Great Britain after the discussions which will doubtless precede any final decision modifying the practice of astronomers, navigators, or others in this country in the reskoning of longitude or time."

The Board of Trade thinks that the resolutions are such as commend themselves for adoption.

The Royal Society forwards a report drawn up by a specially appointed committee, which the Council of the Society adopted :-

"The committee recommend the Council to approve of resolutions $I$ to 6.

"With regard to resolution 6 , if the change of timereckoning be generally adopted, and can without inconvenience to mariners be made in the nautical almanacs of all nations for 1890 , the committee recommend that year for the change to be made.

"With regard to the seventh resolution the committee would remark that, for astronomical reasons, the division of angular space is bound up with the division of time, and that a decimal division of the day would be opposed to the practice of, we may say, all nations, from very early times to the present day.

"Such a change the committee conceive ought not to be made without the gravest consideration. The committee observe, however, that the resolution does not appear to go beyond the expression of a hope that the subject may be further studie 1 , to which of course there can be no objection."

The Eastern and South African Telegraph Company give the same reply as that given by the two Eastern Companies to which we have already referred.

The Submarine Telegraph Company does not adopt the twenty-four-hour system.

The Office of Works has no observations to make.

The Colonial Office has no objections to offer.

The views of the Admiralty were thus stated in a letter dated July I 885 :-

"My Lords desire me to inform you that this question has engaged their attention since the receipt of the communication from the Science and Art Department of the 29th May, but that, seeing how many and varied are the interests involved in a proposal to make any alteration in methods of reckoning time which have for so many hundreds of years prevailed, they have thought it desirable, before offering any opinion, to obtain full information on the results which would follow, and the effect which it might have both on seamen and astronomers, more especially as the main responsibility of action would finally rest on their Lordships, as controlling the production of the Nautical Almanac.

"When their Lordships have received the report of the Board of Visitors to the Royal Observatory, Greenwich, who, as eminent astronomers, have been consulted, they will be in a position to give an opinion; but as they have been advised that that body cannot conveniently meet, without undue haste, until the autumn, their Lordships regret that, for the present, they cannot furnish any definite reply to the question asked by the Lords of the Committee of Council on Education."

The General Post Office letter states that there will be no objection to the adoption of a legally authorised system of counting time from zero to twenty-four hours, and that for some purposes it seems to possess advantages over the present system. The Postmaster-General is inclined to think, however, that, in the case of his Department in particular, the introduction of the system should depend upon popular feeling.

The Elder Brethren of the Trinity House see no objection to the immediate adoption of the sixth resolution, that as soon as may be practicable the astronomical and nautical days will be arranged everywhere to begin at mean midnight.

The above letters are given in the order in which they were received by the Science and Art Department.

In January of the present year, the Admiralty sent a second letter, which we give in extenso:-

"SIR, Admiralty, $5^{\text {th }}$ January, 1886

"I am commanded by miy Lords Commissioners of the Admiralty to inform you that they have had under their careful consideration your letter of the 29th May last, inclosing a copy of the resolutions passed by the International Conference for fixing a Prime Meridian and Universal Day, held at Washington in October 1884 , and asking their Lordships' opinion thereon.

" 2 . The first five of these resolutions, causing as they do a minimum of change in the customs of this country, cannot but meet with their Lordships' unqualified approval, but do not appear to call for any action on their part.

" 3. My Lords do not consider that the seventh resolution demands any remark from them.

" 4 . With regard, however, to the sixth resolution, which proposes a fundamental change in the mode of reckoning astronomical time, my Lords are deeply interested, not only so far as it may affect Her Majesty's Navy, but in consequence of the responsibility for the publication of the Nautical Almanac being vested by Act of Parliament solely in them.

" 5. My Lords are of opinion that the sixth resolution may be regarded in two different lights :-

"Ist. It may be considered as the natural corollary of the adoption of a universal time, such time being a civil day at the Prime Meridian; because, should universal time be adopted (for scientific and certain other purposes) the disagreement between civil and astronomical time, if retained, would to a great degree render nugatory the endeavour to introduce uniformity. In this aspect the change would seem to depend upon the adoption of universal time.

" 2 nd. This proposed change may also, however, be looked upon as intrinsically desirable in itself, besides as in a measure facilitating the adoption of universal time; and in this light action may be taken before any international consensus is arrived at with regard to universal time as recommended by the Washington Conference.

" 6 . Before, however, coming to any final conclusion on the advisability of sanctioning such changes in the ephemeris as would be necessary to give effect to this resolution, my Lords have felt bound to consult, both as to the principle and in respect of details, those other classes who habitually use the Nautical Almanac, viz., the mercantile marine and astronomers, as represented respectively by the Board of Trade and by the Board of Visitors to Greenwich Observatory, the latter being the most representative body of astronomers to whom my Lords could appeal.

"7. My Lords find that, while there is a general agreement in the desirability of putting an end to the present dual system of reckoning time, the urgency of the change is differently regarded by seamen and astronomers. 
“8. Astronomers are now apparently finding many difficulties in the present duplication of time, and are desirous of a speedy change.

"9. At sea it causes but little practical inconvenience, as the two systems do not come into collision, being used for totally different purposes; and my Lords agree with the opinion expressed to them by the Board of Trade, that the change will not be unattended with risk from the possibility of mistakes during the period of transition, and that it must be made with all possible precautions.

"My Lords also fully recognise that the fact of the change rendering the existing epitomes and text-books of navigation to a great extent useless must receive due consideration from several points of view.

"Io. It does not, however, appear to my Lords that there is sufficient reason to cause them to place obstacles in the way of making the change desired by British astronomers and many seamen, and recommended by the unanimous votes of the Delegates of the Washington Conference, as they consider that the rearrangement of the Nautical Almanac may be so carried out as to minimise the above-mentioned risks.

"II. My Lords will, therefore, be prepared to sanction such alterations in the Nautical Almanac as will be necessary to establish the change to the new reckoning at a date sufficiently far in advance to give ample warning to seamen.

"I2. As, however, the fundamental objects in view of the Washington Conference were, to simplify and unify the modes of reckoning time, to remove present discrepancies, and to endeavour to establish an international system, it would appear that no decided move of any kind should be made until the views of other nations, and more especially those maritime powers which publish astronomical ephemerides, are ascertained. It would be manifestly contrary to the interests of simplification that England should alter the practice of centuries only to find herself alone in the new method of reckoning astronomical time ; nor would it be courteous to announce her intention of so doing without consulting other Governments on the steps proposed by their representatives, but not plenipotentiaries, at the Washington Conference.

"13. My Lords will, therefore, be pleased to learn that the opinions and intentions of the other maritime nations have been ascertained at as early a date as practicable, in view of the wishes of British astronomers.

$$
\text { "I am, \&c. }
$$

"(Signed) EVAN MACGREGOR.

\section{"The Secretary, Science and Art Department, "South Kensington, S.W."}

After the receipt of the second letter from the Admiralty another meeting of the committee was held, and the following report was drawn up for the information of my Lords :-

"Your committee find that the Science and Art Department having consulted the various bodies named in the accompanying list, the first five of the resolutions of the Washington Prime Meridian Conference have received unanimous approval, but demand no action on the part of this country.

"As regards the sixth resolution, which proposes that as soon as may be practicable the astronomical and nautical days shall be arranged everywhere to begin at mean midnight, it appears that the opinion in England is generally in favour of this change in the mode of reckoning astronomical time, and that the Admiralty have expressed their willingness to take the necessary steps to give effect to this resolution of the Conference by introducing civil reckoning into the British Nautical Almanac, the rearrangement of which they are satisfied may be so carried out as to minimise risks from mistakes by navigators during the period of transition, if other maritime nations are pre- pared to adopt the proposed method of reckoning astronomical time.

"Under these circumstances your committee suggest that the Foreign Office be invited to communicate this result of the inquiries of the Science and Art Department to the Government of the United States, and to inquire whether, as conveners of the Washington Conference, they are now prepared to take steps to invite the adhesion of other maritime States"

Next follow; a letter from the Science and Art Department to the Foreign Office, asking them to make the inquiry referred to in the previous report, and another from our ambassador at Washington, stating that the United States Government had taken the matter in hand.

\section{FACILITIES FOR BOTANICAL RESEARCH}

$\mathrm{I}$ an article under the above heading, published in NATURE, vol. xxxi. p. 460 , I endeavoured to draw the attention of our younger botanists to the importance of extending their studies over a wider field than is at present usual, and mentioned some easily accessible stations at which students might observe tropical vegetation. Since that article was written, I have had the opportunity of acting on my own suggestion, and of visiting Ceylon; I am therefore now in a position to enlarge upon my previous suggestions, and to fill in from personal experience many details which, though often trivial in themselves, may yet bring the possibility of Eastern travel home to the mind of some in such a way as may lead to future action. But while giving some account of the facilities for botanical work in the East, care must be taken not to over-colour the picture; it happens too often that writers of an enthusiastic bent raise expectations in the minds of their readers, which actual experience can only disappoint: in the following paragraphs I shall endeavour to make a purely matter-of-fact statement, and leave the colouring to be filled in at the will or opportunity of the reader. Taking first Peradeniya, we may consider what are its attractions as a station for botanical work, and then pass on to discuss the relative merits of other stations.

In the first place, hardly any port in the east is more accessible than Colombo: it has been aptly called the "Clapham Junction" of the East: the steamers of all nations meet there, and the competition between them produces a moderate scale of fares. Once there, a direct train service lands the traveller in about three hours almost at the gate of the Royal Gardens; the mechanical discomforts of many a journey to remote districts in the United Kingdom are greater than this. The cost of the journey will vary according to the line of steamers selected; by the Peninsular and Oriental line a return ticket can be had from London to Colombo for $90 \mathrm{l}$., iool, or i $10 l$., according as the return journey is completed in three, six, or twelve months. The charges on the Messageries Maritimes are about the same. The Star, Clan, and British India lines make more moderate charges, but the pace is correspondingly slower. It is little use making a journey of more than 5000 miles for a brief visit; and it may be presumed that, except where the circumstances are extraordinary, students would find it convenient to stay in Ceylon for three or four months, or more. Little is to be gained by scamping an expedition such as this, in which it may often happen that a man may gain his first and last experience of tropical nature; further, the surroundings are so new that it is some little time before one with even a good knowledge of our temperate flora can accommodate himself sufficiently to them to carry on successful work. We may then regard the cost of the journey as rool., and the time required to make it a success about six months. The choice of season is an important point: in a country of alternating wet and dry 